\title{
The National Service Training Program of State Colleges and Universities: An Assessment
}

\author{
Alodia D. G. Zapata \\ Bulacan State University, Malolos, The Philippines \\ Email: alodiazapata@yahoo.com
}

Received 8 September 2015; accepted 23 September 2015; published 28 September 2015

Copyright (C) 2015 by author and OALib.

This work is licensed under the Creative Commons Attribution International License (CC BY). http://creativecommons.org/licenses/by/4.0/

(c) (i) Open Access

\section{Abstract}

This research focused on the extent of implementation of the features of National Service Training Program in terms of program vision and mission, services and activities offered, budget allocation, supplies and materials used, personnel and faculty involved, and seminars and training conducted for facilitators and implementers. Likewise, it looked on the extent of attainment of the objectives of the program as perceived by the administrators and facilitators of the program and finally the level of competencies of students enrolled in (Reserve Officers Training Corps) ROTC, (Civic Welfare and Training Service) CWTS and (Literacy Training Service) LTS. This study evaluated the existing national service training program of selected state universities in Region III, in which the findings could be used as the basis for the program enhancement of the aforementioned state universities. In addition, the study sought answers on questions of the implementers profile, the extent of implementation of NSTP in terms of programs' mission, goals and objectives, services and activity conducted, adequacy of funds and resources, facilitation and equipment and the personnel and faculty involved. Likewise, the level of competencies of the students had been evaluated under the component of ROTC, CWTS and LTS and their awareness on values, concept of community, dimensions of development and contemporary issues in nation building. The program has been evaluated based on the criteria of effectiveness, efficiency, responsiveness, adequacy, equity and appropriateness. The program has demonstrated its capability of filling in the economic, socio-cultural, political, and information components of national security and development, enhancing welfare of communities in contributing to the overall peace, development and national security. The implementer respondents evaluated NSTP program as effective, efficient, responsive, adequate, with equity, and appropriate to its intended purpose.

\section{Keywords}

National Service Training Program, Evaluation, State Universities

Subject Area: Education 


\section{Introduction}

The precept that democracy is the government of the people by the people and for the people has always been reiterated. The college students as the people in a democratic society are recognized to be citizens who are expected to exemplify the principle of participatory democracy. Likewise, they are looked up to as a huge pool of human resources in nation-building.

In this regard, the constitution mandates citizenship training and education of the Filipino youth that should commence as early as the elementary grade and continue through high school up to college.

Like the United States of America, the Philippines has its Armed Forces in charge of preserving the integrity and independence of the Philippines as a state. Since not all can become official defenders of the state, citizens undergo special training, in case that their cooperation will be needed to ensure state's self-preservation. And so, the Citizen's Army Training (CAT) was introduced in the High School curriculum and the Reserved Officers Training Corps (ROTC) in college.

\subsection{Significance of the Study}

The researcher believes that this study will be able to expound on the nature and significance of the National Service Training Program of tertiary educational institutions to the students and to the community it serves. Specifically the findings of this study will benefit the following: administrators can realize the problem and challenges of the programs and services being delivered by the school; hence improvement of the program can be implemented by way of policy recommendation, reformulation, and redirection especially on realizing how these program and services can be considered to improve the services and activities that may not produce good results and continue with the projects and under takings that are worth continuing.

It will challenge the university to qualify whether the services offered are relevant, functional and aspiration of the beneficiaries. The community will benefit most from the result of this study in the sense that it will direct all the efforts for the development and improvement necessary to the program that are responsive to the needs of the communities concerned.

\subsection{Scope and Delimitation of the Study}

The scope of this study was focused on the analysis of the performance evaluation of the National Service Training Program of Selected State Universities and Colleges in Region III, during the school year 2014 to 2015.

The core of the study was to determine the extent of implementation of the National Service Training Program of Selected State Universities in Region III, to find out if these state universities provided the same or different activities that were relevant, functional, and responsive to the needs of the community they served.

The study delimits to selected State Universities in Region III, namely, Bataan Peninsula State University (BPSU), Bulacan State University (BulSU), Don Honorio Ventura Technological State University (DHVTSU), Nueva Ecija University of Science and Technology (NEUST), Ramon Magsaysay Technological University (RMTU), and Tarlac State University (TSU).

The respondents were the bonafide students of State Universities who had taken the NSTP 1 being offered every first semester of the academic year and NSTP 2 which was offered every second semester of the same year.

A locally constructed questionnaire was developed by the researcher based on the statements of the problems, the respondents' profiles and the features' components of the National Service Training Program, on the attainment of the program objectives and on the competencies developed among the students after taking the program. It was validated by competent research panelist.

The study delimits to six selected SUCs represented in Table 1.

Table 1 showed the population of the study, which included school administrators, i.e., associate directors of program and faculty members who facilitated the program and students who had taken up NSTP 1 and NSTP 2 subject.

Questionnaires and interviews were utilized in gathering the needed data and information. The data gathered were analyzed using the frequency distribution, ranking, and mean to describe the data.

\section{Conceptual Framework}

The conceptual framework shown in Figure 1 is based on an input-process-output (IPO) model. 
INPUTS

\begin{tabular}{|c|c|c|}
\hline $\begin{array}{l}\text { - Implementing rules and } \\
\text { regulations of RA } \\
\text { 9163-NSTP } \\
\text { - Related literature and } \\
\text { Studies } \\
\text { - Pertinent documents } \\
\text {-Books/newspapers } \\
\text { Researches, } \\
\text { Theses, } \\
\text { Dissertations, } \\
\text { Articles, Journals from } \\
\text { various libraries } \\
\text { Web pages, } \\
\text { - Interviews }\end{array}$ & $\begin{array}{l}\text { - Construction and Validation of } \\
\text { Questionnaires } \\
\text { - Presentation and identification of } \\
\text { the: } \\
\text {-program implementers' profile } \\
\text {-features of the NSTP components } \\
\text {-attainment of the objectives } \\
\text {-level of competencies of students } \\
\text { - Evaluation of NSTP in terms of: } \\
\text {-effectiveness } \\
\text {-efficiency } \\
\text {-equity } \\
\text {-adequacy } \\
\text {-responsiveness } \\
\text {-appropriateness }\end{array}$ & $\begin{array}{c}\text { Evaluated } \\
\text { NSTP } \\
\text { program } \\
\text { of } \\
\text { Selected } \\
\text { SUCs in } \\
\text { Region } \\
\text { III }\end{array}$ \\
\hline
\end{tabular}

Figure 1. The conceptual model of the study.

\begin{tabular}{|c|c|c|c|c|c|}
\hline \multirow{2}{*}{ Selected SUCs in Region III } & \multirow{2}{*}{ Implementors } & \multicolumn{3}{|c|}{ Students } & \multirow{2}{*}{ Total } \\
\hline & & ROTC & CWTS & LTS & \\
\hline Bataan Peninsula State University & 9 & 30 & 30 & 15 & 84 \\
\hline Bulacan State University & 31 & 30 & 255 & 42 & 358 \\
\hline Don Honorio Ventura Technological State University & 14 & 30 & 84 & 18 & 146 \\
\hline Nueva Ecija University of Science and Technology & 12 & 30 & 78 & 18 & 138 \\
\hline Ramon Magsaysay Technological University & 17 & 30 & 93 & 17 & 157 \\
\hline Tarlac State University & 15 & 30 & 96 & 18 & 159 \\
\hline Total & 98 & 180 & 636 & 128 & 1,042 \\
\hline
\end{tabular}

The first block is the input which is the various NSTP components like implementing guidelines, the related literature and studies, pertinent documents, researcher, thesis, dissertation, interviews.

The second block represents the process employed to the data, utilization of a locally structured questionnaire, profile of program, implementation, features of NSTP components and level of competencies of students per components.

Indicated in the third block is the output which is the result of the evaluation of the NSTP program.

Republic Act 9163 was an act established for tertiary level students amending for the purpose of Republic Act No. 7077 and Presidential Decree No. 1706 and for other purposes This act which is a consolidation of H.B. No. 3595 and S.B. No. 1824 was finally passed by the House of Representatives and the Senate on December 19, 2001 otherwise known as National Service Training Program enacted to conduct capability enhancement for civic welfare services geared towards strengthening the values, and traits of the youth, develop social entrepreneurs, volunteers, and socio-economic, mobilizing force, serving communities as value-driven innovations for progress and development while working closely with a network of organizations within and outside the higher education institution [1].

Under the implementing Rules and Regulations of RA 9163 provides that the NSTP shall have the following components that the students can choose from: The Reserve Officers Training Corps (ROTC); The Literacy Training Service (LTS); and The Civic Welfare Training Service (CWTS).

ROTC, as component, of course, has retained with its primary aim to prepare, the youth in national defense. LTS, on the other hand, has a more limited yet equally useful objective that is to "train students to become teachers of literacy and numeracy skills to school children, out of school youth, and other segments of society in need of their service". With this, LTS therefore specializes in the education of the people, and in strengthening the education sector to empower the people through education. The last component, CWTS involves activities 
that have social and those that could contribute to health, education, environment, entrepreneurship, safety, recreation, and morals of the citizenry. The students are trained to become volunteers for the general welfare of marginalized communities. CWTS additionally focuses on supplementing various facts of volunteer workers, such as infrastructure, social welfare assistance, rescue operation, workers by way of government and community development organizations, medical missions such as those of Red Cross and Department of Health and various ecology-based projects, such as the planting activities. The CWTS component, therefore, prioritizes the involvement of the youth in broad programs or activities that will benefit the people.

Criteria for Policy Evaluation. The criteria on summative evaluation developed in 1994 [2] served as the basis on the assessment of this study. These criteria are: effectiveness, efficiency, adequacy, equity, responsiveness, and appropriateness. He clarifies that a program is effective if it results in the achievement of valued outcome of action. According to him effectiveness is measured in terms of units of products. In connection to the present study, the researcher would follow the line of this theory by looking into the perception of the respondents to the effectiveness of the National Service Training Program. In addition, he defines efficiency as the amount of effort required to produce a given level of effectiveness. Using this measure, this is relative to their formulation and implementation of the program policies. He further argued that a program can be evaluated in terms of its adequacy. This criterion relates to the level of effectiveness which leads to satisfying the needs, values, or opportunities that give rise to the problem.

The Context-Input-Process-Product (CIPP) Evaluation Model. The CIPP Model [3], for the evaluation of innovations in education, attempts to maximize the effectiveness of critical decisions through the timely reporting of relevant information in a useful form to appropriate levels of decision making. Evaluation is thus seen as the combination of effective decisions based on timely relevant information. The CIPP Model is a comprehensive frameworks for guiding formative and summative evaluation of projects, programs, personnel, products, institutions, and system [4]. Likewise, according to the CIPP Model, evaluation is a systematic investigation of the value of a program. There are four concepts denoted by the acronym CIPP, which stands for evaluation of an entity's context, inputs, processes, and products.

Pluralist View on Evaluation. The first evaluator to propose the pluralist argument [5] states that the evaluator should be informed on certain standards to be employed. He emphasized that the needs of those concerned must be addressed in the evaluation and what the clients need from the program evaluation must be discovered even before the evaluation project is designed. In the evaluation process, he laid less emphasis on precisely specified objectives, because he believed that all intentions even those that were not explicitly expressed in terms of student learning must be described. For him, an evaluator should report the ways different people (the stakeholders) see the curricular program. In evaluating a program principal activities include discovering what the stakeholders want to know, making observations, and gathering judgments about the observed transactions and outcomes. A variety of persons - teachers and students - may participate in the conduct of the evaluation [6].

Multiple Perspective View on Evaluation. Another equally relevant issue pertaining to evaluation is who will conduct program evaluation or who will be involved in this process. As cited by [6] [7] believes that evaluation requires multiple perspective on what constitutes knowledge by people in the school. By multiple perspective of course, it means involving a wide range of respondents who directly benefit from the program. For [7], evaluation is a rigorous process of critical inquiry which itself a dialectic approach. According to him critical inquiry enables the evaluator to collect varied and pertinent information in which the data are not limited to quality indicators and test scores that lend scientific credibility to superficial accountability systems. He summed up his evaluation as being a valuing activity in which evaluators express their values, beliefs, interests and ideologies as they critically examine school practices or programs.

They are three purposes served by evaluation [8]: 1) to improve the design or delivery of learning events; 2) increase the use of the learning on the job; 3 ) to make decisions about learning in the organization. She points out that evaluation for the purpose of improving the delivery of a learning event involved a number of measures. Among these is on profile of those who were successful in learning and those who were less successful. It is also equally important to identify the characteristics which can be correlated with the results of performance measures in order to provide better information on how to target the learning event.

The five functions of evaluation [9] are the following: 1) to diagnose the weakness of the curriculum, of teaching, and of students learning to serve as a basis for change; 2) revise the curriculum as feedback mechanism for improvement; 3) compare curricular to improve information on what to adopt, implement, or expand; 4) identify educational objectives based on what the student and the community needs; 5) determine if the objectives have been achieved. 


\section{Research Method}

The study used the descriptive type of research. Gathered data using the survey instrument were used to describe the following: respondent's profile, extent of implementation of the different features of the National Service Training Program (NSTP), extent of attainment of the program's objectives, level of competencies of students on the objectives of the program, and the evaluation of the NSTP.

Respondents of the study were limited to the randomly selected ninety eight (98) implementers (administrator and facilitator), one hundred eighty (180) ROTC students, six hundred thirty six (636) CWTS students, and one hundred twenty eight (128) LTS students.

The data gathered were summarized in a tabular form, analyzed and treated statistically. Descriptive statistical tools like frequency, mean and standard deviation were used to describe the characteristics of the respondents as well as their perception regarding different NSTP's concerns.

\section{Summary of Findings}

Table 2 reveals the profile of the implementers: in the average they are 43 years old, most of them are female, the group is dominated by married members, and majority of them have an educational attainment of BS degree with earned units in the Master's Program.

This further reveals that the National Service Training Program appear to be attractive assignments among middle aged and experienced faculty members. However, since the nature of the program especially NSTP 2Civic Welfare Training Service which focus more on community service and task intensive, more senior faculty member find it physically taxing and as a result of this, only three respondents aged between 66 and 70 years old (part-timers) and five respondents aged between 61 and 65 years old respectively are involved.

Table 2. Profile of the program implementors.

\begin{tabular}{|c|c|c|c|c|}
\hline & Variable & Frequency & Percentage & Mean \\
\hline \multirow{10}{*}{$\begin{array}{c}\text { Age } \\
\text { (years) }\end{array}$} & $66-70$ & 3 & 3.06 & \multirow{20}{*}{43.30} \\
\hline & $61-65$ & 5 & 5.10 & \\
\hline & $56-60$ & 6 & 6.12 & \\
\hline & $51-55$ & 10 & 10.20 & \\
\hline & $46-50$ & 11 & 11.22 & \\
\hline & $41-45$ & 19 & 19.40 & \\
\hline & $36-40$ & 17 & 17.35 & \\
\hline & $31-35$ & 16 & 16.33 & \\
\hline & $26-30$ & 10 & 10.20 & \\
\hline & $21-25$ & 1 & 1.02 & \\
\hline \multirow{3}{*}{ Gender } & Female & 62 & 63.30 & \\
\hline & Male & 36 & 36.70 & \\
\hline & Single & 18 & 18.40 & \\
\hline \multirow[t]{4}{*}{ Civil status } & Married & 73 & 74.50 & \\
\hline & Widowed & 7 & 0.70 & \\
\hline & $\mathrm{PhD} / \mathrm{EdD}$ & 2 & 2.00 & \\
\hline & MA/MS with $\mathrm{PhD} / \mathrm{EdD}$ units & 19 & 19.40 & \\
\hline \multirow[t]{3}{*}{$\begin{array}{c}\text { Educational } \\
\text { attainment }\end{array}$} & MA/MS or its equivalent & 37 & 37.80 & \\
\hline & BS with master's units & 38 & 38.80 & \\
\hline & BS & 2 & 2.00 & \\
\hline
\end{tabular}


Great extent was observed in the implementation of the National Service Training Program in terms of the following features: program vision, mission, services/activities offered, budget allocation, facilities, supplies and materials used for NSTP, personnel/faculty involved in NSTP, and seminars/training conducted for the implementers. The vision and mission of NSTP program is well defined, well communicated, spells out its extension programs to the community, and it adheres to the philosophy and values of the institution. A perusal of numerical inputs in this table reveals that different services like medical and dental health care, literacy, conservation of the environment, and the likes are implemented to a great extent level.

Table 3 shows how a budget is a fundamental tool to execute successfully any projects or activities of NSTP program. It helps to aid the planning of actual NSTP operations by forcing implementers to consider how the conditions might change and what steps should be taken now and by encouraging them to consider problems before they arise. The numerical findings indicate that the respective programs of selected State Universities included in this study have the necessary facilities and equipment to sustain such projects and activities. The respondents viewed that there were enough competent personnel in their respective NSTP program components as evidenced by the overall mean rating of 3.91 interpreted as great extent the respondents viewed that there were enough competent personnel in their respective NSTP program components as evidenced by the overall mean rating of 3.91 interpreted as great extent. Implementers of NSTP program were asked to attend seminars/training related to the following concerns: zero waste management, nutrition and basic health care, leadership training program, sports clinic, and workshop. For them, attendances to these seminars and training are adequate or sufficient enough for them to do their role as administrator or facilitator of NSTP program, as indicated by the mean score of 4.11 .

Table 4 shows that the implementer respondents agreed to a great extent that objectives of the program were attained in terms of the following variables: self awareness and values development, management and organizational, basic leadership training, the concept of community, dimension of development, contemporary issues/ current needs in nation building, and community exposure and assessment. In this regard, self-awareness is important in certain discipline as in human relations because we can have a better understanding of ourselves. We are empowered to make change and to build on our areas of strength as well as identify areas where we would like to make improvements. The computed mean score of 4.31 shows that the success of these objectives can be attribu-

Table 3. Extent of implementation of the features of NSTP components.

\begin{tabular}{lll}
\multicolumn{1}{c}{ Features } & Mean & \multicolumn{1}{c}{ Verbal interpretation } \\
\hline $\begin{array}{l}\text { 1) Program vision \& mission } \\
\text { 2) Services/activities offered }\end{array}$ & 4.50 & Great extent \\
3) Budget allocation & 3.05 & Great extent \\
4) Facilities, supplier and materials used for NSTP & 3.68 & Great extent \\
5) Personnel/faculty involved in NSTP & 3.91 & Great extent \\
6) Seminar/training conducted for facilitator/implementors & 4.11 & Great extent extent \\
\hline
\end{tabular}

Table 4. Extent of the attainment of the objectives of the program as perceived by the implementors.

\begin{tabular}{lcc}
\multicolumn{1}{c}{ Objectives } & Mean & \multicolumn{1}{c}{ Verbal interpretation } \\
\hline 1) Self awareness and values development & 4.34 & Great extent \\
2) Management and organizational development & 4.31 & 4.38 \\
3) Basic leadership training & 4.26 & Great extent \\
4) The concept of community & 4.24 & Great extent \\
5) Dimensions of development & 4.14 \\
6) Contemporary issues/current needs in nation building & 4.27 & Great extent \\
7) Community exposure and assessment & Great extent & Great extent \\
\hline
\end{tabular}


ted to the organization like the family which are conscious to make efforts to pass on their values and ideas to their children towards achievement, self-control, modesty simply by observing which behavior tends to be rewarded and which tends to be punished, the school who prepares us for future roles as loyal, humble and punctual employees. Competent leaders act to help a group attain objectives through maximum application of its capabilities, they place themselves before the group as they facilitate progress and inspire groups to accomplish organizational goals. The dimension of development implies that a genuine participatory approach to development is essential for success and sustainability. Civil society participation in development effort is therefore increasingly recognized by agencies and governments as essential for promoting good governance-improving responsiveness of national policies and program to citizens' needs and earning transparency and accountability in policy making and implementation processes of programs like the civic welfare training service (CWTS). NSTP is intended for intensive community exposure for thorough implementation of community plans and projects which will develop the student's value of commitment, hard work and resourcefulness. And one challenge of participation is to seek and make contact with people and through these program activities students are exposed to actual participation.

Table 5 displays the ROTC, CWTS and LTS students were competent in developing themselves in terms of: self awareness and values development, management and organizational, basic leadership training, the concept of community, dimension of development, contemporary issues/current needs in nation building, and community exposure and assessment.

The student respondents under the ROTC program are competent enough on the objective of NSTP program, about issues and concerns on how to preserve and safe guard human life, uphold the rule of law at all times and recognize the characteristics and actions of an effective citizen.

Whereas, CWTS students are competent enough on what they should do for their own good, that they are assets to their family and to the nation, and that they can live not in isolation but in the community of others. On becoming more open to challenges, when obstacles are encountered, having an open mind and willing to accept suggestions from other people as a strategy in community organizing. It is sought to imbibe among NSTP trainees a better understanding of different community concerns through exposure on actual life situation specifically in the deprived, depressed and under privileged communities.

On the other hand, students who had enrolled in LTS component showed competency on the following: competent that truth will prevail and reign on our land, share love and be loved, develop ethics of care and sense of efficacy, be a catalyst of social change, develop innovativeness, can emphasize the positive effect of coordination, be a good leader, can educate people to understand their critical consciousness of the present situation, and the guts to teach problem solving skills in literacy and numeracy to others.

Table 6 contains the implementer respondents evaluated the NSTP program as effective, efficient, responsive, adequate, with equity, and appropriate to its intended purpose.

The NSTP program is effective in realizing its objectives because of the following reasons: there is cooperation among members of implementers, objectives were converted into programs and activities, there is monitoring in the implementation of the program, and finally there is evaluation in terms of attaining the objectives of the program.

Table 5. Level of competencies of the student's on the objectives of NSTP programs.

\begin{tabular}{|c|c|c|c|c|c|c|}
\hline \multirow{2}{*}{ Objectives } & \multicolumn{2}{|c|}{ ROTC } & \multicolumn{2}{|c|}{ CWTS } & \multicolumn{2}{|r|}{ LTS } \\
\hline & Mean & $\begin{array}{c}\text { Verbal } \\
\text { interpretation }\end{array}$ & Mean & $\begin{array}{c}\text { Verbal } \\
\text { interpretation }\end{array}$ & Mean & $\begin{array}{c}\text { Verbal } \\
\text { interpretation }\end{array}$ \\
\hline 1) Self-awareness and values development & 4.29 & Competent & 4.11 & Competent & 4.10 & Competent \\
\hline 2) Management and organizational development & 4.26 & Competent & 3.92 & Competent & 3.87 & Competent \\
\hline 3) Basic leadership training & 4.30 & Competent & 4.04 & Competent & 4.06 & Competent \\
\hline 4) The concept of community & 4.31 & Competent & 4.04 & Competent & 4.01 & Competent \\
\hline 5) Dimension of development & 4.27 & Competent & 4.04 & Competent & 4.08 & Competent \\
\hline 6) Contemporary issues/current needs in nation building & 4.31 & Competent & 4.00 & Competent & 3.91 & Competent \\
\hline 7) Community exposure and assessment & 4.27 & Competent & 4.04 & Competent & 4.11 & Competent \\
\hline
\end{tabular}


Table 6. Evaluation of NSTP program.

\begin{tabular}{lcc}
\hline \multicolumn{1}{c}{ Criteria } & Mean & Verbal interpretation \\
\hline 1) Effectiveness of the program & 4.31 & Effective \\
2) Efficiency of the program & 4.25 & Efficient \\
3) Responsiveness of the program & 4.33 & Responsive \\
4) Adequacy of the program & 4.28 & Adequate \\
5) Equity of the program & 4.20 & Fair \\
6) Appropriateness of the program & 4.25 & Appropriate \\
\hline
\end{tabular}

There is efficiency in meeting its objective since the implementer implements the program plan strictly and fairly, there is saving in finances since the implementer pursued the objectives of the program using the local resources, implementation was done on its target time since the implementation is guided by plans, and sufficiency in man power makes the implementation of the program efficient.

NSTP program is responsive enough because of the good qualifications of the implementers like: they possessed the required education, well knowledgeable on the contexts of the program; they have the technical knowhow necessary for successful implementation, and well experienced.

It is interesting to note that the result of the respondent's evaluation on adequacy gave "adequate" verbal rating in terms of meeting the needs of the participants because of their active participation, the activities are adequate in providing the literacy training needs of the participants, and the objective as well as the activities are adequate because these are specific, measureable, attainable, realistic, and time-bound/based.

The program fairly meets its objective may be because of limited financial assistance extended for the its implementation, implementers were not properly recognized for the job well done by them, and other forms of supports (moral, psychological, etc.) might not that enough to handle the implementation of the NSTP program.

There is appropriateness because the implementers of the program possesses desirable value of love of knowledge, skills and attitude; the implementers have values of perseverance in pursuing program's goal despite of the encountered difficulties; there is a sense of patriotism among implementers; and implementers have dedication in what they are doing.

\section{Conclusions}

Based on the aforementioned findings, the following conclusions are drawn.

As viewed by the National Service Training Program respondents of the six state universities involved in the study, they perceived that the NSTP objectives were not accomplished effectively and that the fund allotment and school facilities were not adequate and the faculty on the other hand, had no necessary/related experience with regard to training to handle for the NSTP subject based on their educational qualification.

There are no significant differences on the perception of the program implementers of the state universities involved in the study using the criteria of evaluation as follows: effectiveness, efficiency, responsiveness, adequacy, equity and appropriateness.

\section{Recommendations}

The following recommendations were posited.

In view of the foregoing recommended program components rated great extent be improved more so that the ratings be raised to a very great extent.

There must be orientation of the programs specifically the objectives, mission vision of the service component namely ROTC,CWTS,LTS to enable the students to choose which components they would like to enroll where they could give their best service to the community intended.

As the leader and master of the classroom, facilitator should act to help the NSTP students attain objectives through the maximum application of their capabilities.

Management should support the program in works and in deeds especially in allotting adequate funds to meet goals; and sufficient budget significantly affects the increase in the student's performance and productivity of 
the facilitators.

There should be enough lecture rooms, facilities rooms conducive to learning and sufficient books and references that will enhance and facilitate learning and awareness of the students about the effectiveness, efficiency, responsiveness, appropriateness equity and adequacy of the program.

There should be strict policy in the recruitment of the teacher who will conduct the program. Would be faculty/facilitator should be screened on the basis of their educational qualification, year of experience in the teaching profession related to the subject handled, participated to relevant trainings and seminars to be able to equipped them with the necessary skills needed in doing community service. This should be done continuously to ensure program success, continuity and better rapport with the people in the community.

Since NSTP is part of the school curriculum and a major function of all state universities, they should further intensify its community service program by utilizing an instrument of its research function. Lastly, the result of this research should be used as basis for the program enhancement.

\section{References}

[1] Gonzales, V. (1997) Implementing Rules and Regulations of Republic Act 9163, National Service Training Program 2001. Values and Integration Promotion Civic Welfare Service. Society Towards Reinforcing Inherent Viability for Enrichment (STRIVE/SIKAP) Los Laguna Handbook on Community Training Programs for Participatory. Central for Rural Technology Development, Philippine Business for Social Progress, Manila.

[2] Dunn, W. (1994) Public Policy Analysis: An Introduction. 2nd Edition, University Pittsburgh Prentice Hall, Englewood Cliffs.

[3] Stufflebeam, D.L. (1968) Evaluation as Enlightenment for Decision. Evaluation Center, Ohio State University, Columbus.

[4] Stufflebeam, D.L. (1983) The CIPP Model for Program Evaluation. In: Madaus, F.F., Scriven, M. and Stufflebeam D.L., Eds., Evaluation Models: Viewpoints on Educational and Human Services Evaluation, Kluwer, Norwell, 117-141. http://dx.doi.org/10.1007/978-94-009-6669-7 1

[5] Stake, R.E. (1979) Should Educational Evaluation Be More Objective or More Subjective? Educational Evaluation and Policy Analysis, 1, 45-47.

[6] McNeil, J. (1996) Curriculum: A Comprehensive Introduction. 5th Edition, Harper Collins, New York.

[7] Sirotnik, K.A. and Kimball, K. (1996) Preparing Educators for Leadership: In Praise of Experience. Journal of School Leadership, 6, 180-201.

[8] Dixon, N. (1990) Evaluation: A Tool for Improving HRD Quality. University Associates.

[9] Morrison, K. (1993) Planning and Accomplishing School-Centered Evaluation. Peter Francis. 